\title{
Pharmaceutical Quality of Antimalarial Drugs: Quinine Sulfate and Artemether/lumefantrine Tablets Sold on Bukavu Market
}

\section{Aladin Ombeni Mahano}

Official University of Bukavu: Universite Officielle de Bukavu

Aline Zawadi Mahano

Official University of Bukavu: Universite Officielle de Bukavu

Nelson Hendwa Cubaka

Official University of Bukavu: Universite Officielle de Bukavu

Félicien Mushagalusa Kasali

Official University of Bukavu: Universite Officielle de Bukavu

Benjamin Bavurhe Zirirane

Official University of Bukavu: Universite Officielle de Bukavu

Lucien Murhula Namegabe

Official University of Bukavu: Universite Officielle de Bukavu

Pacifique Murhula Hamuli

Official University of Bukavu: Universite Officielle de Bukavu

Ntokamunda Justin Kadima ( $\square$ kadima48@yahoo.com )

Official University of Bukavu: Universite Officielle de Bukavu https://orcid.org/0000-0003-0395-7935

\section{Research}

Keywords: Antimalarial medicines, Quality control, Quinine, Artemether, Lumefantrine, Africa

Posted Date: February 19th, 2021

DOl: https://doi.org/10.21203/rs.3.rs-237275/v1

License: (c) (i) This work is licensed under a Creative Commons Attribution 4.0 International License.

Read Full License 


\section{Pharmaceutical Quality Of Antimalarial Drugs: Quinine Sulfate And Artemether/Lumefantrine Tablets Sold On Bukavu Market}

Aladin Ombeni Mahano ${ }^{1}$, Aline Zawadi Mahano ${ }^{1}$, Nelson Hendwa Cubaka ${ }^{1}$, Félicien Mushagalusa Kasali ${ }^{1}$, Benjamin Bavurhe Zirirane ${ }^{1}$, Lucien Murhula Namegabe ${ }^{1}$, Pacifique Murhula Hamuli ${ }^{1}$, Justin Ntokamunda Kadima $^{1 *}$

${ }^{1}$ Department of Pharmacy, Faculty of Pharmaceutical Sciences and Public Health, University Official of Bukavu, DR Congo

${ }^{*}$ Corresponding author: Justin Ntokamunda Kadima, Department of Pharmacy, School of Medicine and Pharmacy, University of Rwanda, ntokamunda13@gmail.com, kadima48@yahoo.com

\section{Abstract}

Background: Malaria is a tropical parasitic disease caused by Plasmodium species, mainly falciparum, transmitted by the female Anopheles mosquito, strongly affecting sub-Saharan Africa and Indian areas. Generic antimalarial drugs sold in these regions require tighter quality control as counterfeiting has grown more and more out of control. The study aimed to analyze the pharmaceutical quality of Quinine sulfate and Artemether/Lumefantrine tablets marketed in Bukavu city compared to current trends in other African cities.

Methods: We set up 13 simple TLC and UV spectrometric quality-control tests and applied them to analyze five Quinine brands divided into 12 batches and two Artemether/Lumefantrine brands divided into 12 batches. Quality scores were expressed as a percentage of compliance with each or the whole set of 13 tests. The samples were collected from community pharmacies and ambulatory street vendors. For comparison, available literature data related to the subject was retrieved from Google Scholar and PubMed search.

Results: The analysis showed $16.6 \%$ of QS batches failed quality specifications concerning hardness, friability, and uniformity of mass; $66.6 \%$ failed the disintegration test; $33.3 \%$ did not contain quinine, and $8.33 \%$ had an active ingredient other than quinine. Only 3 batches exhibited a global score $>90 \%$. For Artemether/Lumefantrine, $93 \%$ of batches had an acceptable quality score $>90 \%$.

Conclusion: The findings strongly support literature data from many countries. Simple TLC procedures may help to detect any low-quality generics to avoid microbial resistance and guarantee the health of the population. Pharmacists and regulatory authorities are alerted to the circulation of low-quality generic quinine preparations in the country.

Keywords: Antimalarial medicines, Quality control, Quinine, Artemether, Lumefantrine, Africa

\section{BACKGROUND}

Malaria is a parasitic disease caused by Plasmodium species, mainly falciparum, and transmitted by female anopheles mosquito bites [1]. Around 3.2 billion people, or almost half of the world's population, are exposed to malaria risk [2-4]. According to the World Malaria Report (WMR), an estimated 228 million malaria cases occurred worldwide in 2018, and 19 countries in sub-Saharan Africa and India carried almost $85 \%$ of the global malaria burden [1]. Of an estimated 405,000 deaths from malaria globally, nearly $85 \%$ are concentrated in 20 countries in the WHO African Region, mostly Nigeria (24\%) 
and the Democratic Republic of Congo (DRC) $(11 \%)[5,6]$. Children aged under five years are the most vulnerable group affected by malaria; they accounted for $67 \%$ (272 000) of all malaria deaths worldwide in 2018.

Access to effective and quality antimalarial drugs (AMDs) plays a crucial role in efforts to ensure complete cures and avoid vicious complications [7]. Without treatment, malaria can quickly lead to death from the circulatory disorders it causes. Also, in many parts of the world, malaria parasites have become resistant to several AMDs, due in significant part to the use of fake medications [8-10]. Among those counterfeit medicines, some contain sub-therapeutic doses and others not at all [11]. According to the Molecular Quantitative Similarity Analysis (MQSA) study, 25-50\% of AMDs are of low quality, adulterated, or of inferior quality. The figures from the United States Food and Drug Administration (USFDA) indicate that up to $25 \%$ of all drugs consumed in emerging countries are counterfeit or substandard [12-14]. Counterfeiting affects all classes of drugs, but mainly antibiotics and AMDs, for which the demand is high in African countries where malaria is endemic. That demand leads to an informal trade in counterfeit products beyond the control of health authorities.

In the DRC, an estimated $97 \%$ of the population lives in zones with stable malaria transmission lasting 8 to 12 months per year; the other $3 \%$ is exposed to epidemic malaria in the high mountains of the East of the country $[15,16]$. Around $80 \%$ of deaths occur at home, which represents millions of cases of death per year. The prevalence of fever in children under five years of age is $42 \%$, which corresponds to between 6 and 10 malaria episodes per child per year. The combination Artemether/Lumefantrine (CoArtem) and Artesunate/Amodiaquine (AS-AQ) are the most widely used AMDs in the initial treatment of non-severe falciparum malaria, and quinine for severe cases [17]. The circulation of counterfeit or poor-quality products is beyond control. This study aimed to assess the quality of generic Quinine sulfate (QS) and Artemether-Lumefantrine (AL) tablets marketed in Bukavu using simple usual analytical techniques.

\section{MATERIALS AND METHODS}

\section{Study area and design}

The study was conducted in Bukavu city, the capital of South-Kivu province in DRC, from May to September 2019. It was designed as an analytical experiment completed by a literature review to evaluate the quality of pharmaceutical quality of Quinine sulfate and Artemether/Lumefantrine preparations dispensed in Bukavu city during the period of investigation and make comparison with current trends observed in other African cities. We conducted pharmaceutical technology tests as prescribed in referral pharmacopeia, including labeling, physical examinations, disintegration time, friability, mass uniformity, followed by identification and quantification of active ingredients. We used thin-layer chromatography (TLC), non-aqueous protometry, and UV-spectrophotometry. All methods were carried out following relevant guidelines and regulations.

The literature search was conducted via Google Scholar and PubMed using the medical subject headings (MeSH) terms: 'Quinine /quality analysis' OR 'Artemether/quality analysis' OR 'Lumefantrine/quality analysis' AND 'Africa' [MeSH]' to find articles published up to 2020. We summarized the data under the following critical attributes: labeling quality, general tests on pharmaceutical dosage forms, content and dissolution, identification, and the presence of unidentifiable impurities in formulations. 


\section{Materials and reagents}

\section{Equipment/Solvents/Reagents}

We used UV-Spectrophotometer (Pharmacia LKB Ultrrospec Plus); Chromatographic plates (Pre-coated TLC sheets Alugram ${ }^{\circledR}$ Xtra Sil G / UV 254 Layer: 0.20 mm silica gel 60 with fluorescent indicator UV 254 ); UV lamp 254nm (Technology transfer Marburg); Analytical balance (Balance digital jewelry scale, Capacity $20 \mathrm{~g}$, readability $0.001 \mathrm{~g}$, China); Friability device (Manufactured by lab-line instruments. Inc. Model ${ }^{\circ} 1641$ ); Aggregation device (Erweka-apparate bau, Western Germany); Durometer (Schleuniger2E, Switzerland); Hot plate (Protherm, Winn Leek-Holland); Water bath (Gerhardt Bonn, Germany); Rotavapor (Pleuger, Switzerland); Centrifuge (IEC Centra-2 centrifuge); vortex shaker (Vortex-2 genie Bohemia NY, USA). We used distilled water, toluene R (Merck KGaA, 64271 Darmstadt. Germany, UN $1294,0.867$ ), Ethyl acetate R (Merck KGaA, 64271 Darmstadt. Germany, 0.9245), Methanol R (Maprochim-Labo, 59, Kinshasa-Gombe / RDC, lot 0112, 90\% 0.791), Hydrochloric acid R (PANREAC Quimica SAU, E-08211 Castellar del Vallès (Barcelona), 37\%, density 1.19), Glacial acetic acid R (BN: 04H240011, EC label: 2005807, made in EC-Emb 45053), Acetic anhydride R (E. Merck Darmstadt, Helliges Reagents R 104, 1.08), Acetone R (Merck KGaA 64271 Darmstadt, Germany), Perchloric acid R (E. Merck, D-6100 Darmstadt, FR Germany, 70\%, density 1.76), Chloroform R (Prolabo, Belgium), Potassium lodide R (Merck, D-6100 Darmstadt, FR Germany), Mercury Chloride II R (B Zedelgem).

\section{Study samples}

The samples of generic $Q S$ and $A L$ tablets analyzed were from the community pharmacies and ambulatory street vendors. As shown in Table 1, we randomly sampled 12 batches of QS tablets, consisting of 30 tablets each from five brands and 12 packs of 24 tablets per blister from two different AL brands.

Table 1. Samples of Quinine Sulfate and Artemether-Lumefantrine brands tested

\begin{tabular}{|c|c|c|c|c|c|c|c|c|c|}
\hline \multicolumn{5}{|c|}{ Quinine sulfate tablets samples } & \multicolumn{5}{|c|}{ Artemether-Lumefantrine tablets samples } \\
\hline $\mathrm{N}$ & Batch & Dose & Shelf-life & Country & $\mathrm{N}$ & Batch & Dose & Shelf-life & Country \\
\hline 1 & QSB1.1 & $500 \mathrm{mg}$ & 5 years & DR Congo & 1 & ALB1.1 & $20 / 120 \mathrm{mg}$ & years & Uganda \\
\hline 2 & QSB1.3 & $500 \mathrm{mg}$ & 5 years & DR Congo & 2 & ALB1.4 & $20 / 120 \mathrm{mg}$ & 3 years & Uganda \\
\hline 3 & QSB1.8 & $500 \mathrm{mg}$ & 5 years & DR Congo & 3 & ALB1.5 & $20 / 120 \mathrm{mg}$ & 3 years & Uganda \\
\hline 4 & QSB1.9 & $500 \mathrm{mg}$ & 5 years & DR Congo & 4 & ALB1.7 & $20 / 120 \mathrm{mg}$ & 3 years & Uganda \\
\hline 5 & QSB1.11 & $500 \mathrm{mg}$ & 5 years & DR Congo & 5 & ALB1.8 & $20 \mathrm{mg}$ & ars & Uganda \\
\hline 6 & QSB2.2 & $500 \mathrm{mg}$ & 6 years & $?$ & 6 & ALB1.9 & $20 / 120 \mathrm{mg}$ & 3 years & Uganda \\
\hline 7 & QSB2.4 & $500 \mathrm{mg}$ & 2 years & $?$ & 7 & ALB1.11 & $20 / 120 \mathrm{mg}$ & 3 years & Uganda \\
\hline 8 & QSB3.5 & $500 \mathrm{mg}$ & $?$ & $?$ & 8 & ALB1.12 & $20 / 120 \mathrm{mg}$ & 3 years & Uganda \\
\hline 9 & QSB4.6 & $500 \mathrm{mg}$ & $?$ & $?$ & 9 & ALB2.2 & $20 / 120 \mathrm{mg}$ & 3 years & Turkey \\
\hline 10 & QSB5.7 & $500 \mathrm{mg}$ & 5 years & Netherland & 10 & ALB2.3 & $20 / 120 \mathrm{mg}$ & 3 years & Turkey \\
\hline 11 & QSB5.10 & $500 \mathrm{mg}$ & 4 years & Netherland & 11 & ALB2.6 & $20 / 120 \mathrm{mg}$ & 3 years & Turkey \\
\hline 12 & QSB5.12 & $500 \mathrm{mg}$ & 5 years & Netherland & 12 & ALB2.10 & $20 / 120 \mathrm{mg}$ & 3 years & Turkey \\
\hline
\end{tabular}

\section{Testing procedures}

\section{Uniformity of mass}


We weighed 20 tablets and calculated the average mass. The deviation of the individual weight of tablets from the mean weight should not exceed $\pm 5.0 \%$ for minimum 18 tablets and $\pm 10.0 \%$ for a maximum [18].

\section{Friability of tablets}

We used a friability device (Manufactured by lab-line instruments. Inc. Model $n^{\circ} 1641$ ) operating by rotation at 100 revolutions per $4 \mathrm{~min}$. We introduced in the machine a total of tablets corresponding, as near as possible, to $6.5 \mathrm{~g}$. According to the requirement, the maximum acceptable loss of mass (obtained from a single test or the mean of 3 tests) is not greater than $1.0 \%$ for the sample [19].

\section{Hardness-Resistance of tablets to crushing}

A durometer (Schleuniger-2E, Switzerland) was used to measure the minimum and maximum force (newton) to crush each of 10 tablets [20].

\section{Disintegration of tablets}

We used the 6-tube basket disintegrating device Erweka-apparate bau (Western Germany) containing hydrochloric acid solution 1 normal $\left(\mathrm{HCl} 1 \mathrm{~N}\right.$ ) as immersion fluid maintained at $37 \pm 2{ }^{\circ} \mathrm{C}$. The basket filled with 6 tablets was rotated for 30 minutes and then raised to count the units not completely disintegrated. The test was repeated three times. At least 16 of the 18 dosage units tested should disintegrate in time $[21,22]$.

\section{Identification of quinine sulfate by Mayer reagent}

A tiny amount of crushed tablets powder was mixed with distilled water, filtered, and the filtrate mixed with the Mayer reagent ( $5 \mathrm{~g}$ of Potassium lodide (KI), $1.36 \mathrm{~g}$ of mercury chloride $\left(\mathrm{HgCl}_{2}\right.$ ), and $100 \mathrm{ml}$ of distilled water) in a test tube. The reaction was positive if a yellowish-white precipitate is formed [23].

\section{Identification of quinine sulfate and Artemether-Lumefantrine by TLC}

The protocol was adapted from the existing procedures. For QS samples [24-26], the stationary phase was silica gel R6; the mobile phase was methanol/ammonia (20: $0.5 \mathrm{v} / \mathrm{v})$. The dilution was carried out up to the final concentration of $1.428 \mathrm{mg} / \mathrm{ml}$. For AL samples [27, 28], the stationary phase was silica gel R6; the mobile phase was toluene/ ethyl acetate/ anhydrous acetic acid (18:4:2 v/v/v). The dilution was carried out up to the final concentration was $1.30 \mathrm{mg} / \mathrm{ml}$ of Artemether and $7.80 \mathrm{mg} / \mathrm{ml}$ of Lumefantrine. Approximately $2 \mu \mathrm{l}$ of samples and $2 \mu \mathrm{l}$ of standards were spotted at $1.5 \mathrm{~cm}$ on silica gel R6 plates. After migration, each plate was removed, dried, and then examined with ultraviolet light (254 $\mathrm{nm})$ for $\mathrm{QS}$ samples. The identification of AL samples required spraying the plate with sulfuric acid $\mathrm{R} /$ methanol $\mathrm{R}$ mixture $(10: 190 \mathrm{v} / \mathrm{v})$ and then heating the chromatographic plate to dryness on the heating plate at $50^{\circ} \mathrm{C}$ for approximately 10 minutes. We compared the correspondence in position, appearance, and intensity between the test-samples and the standards. The retardation factor error (\%RF error) of Rf-sample and Rf-standard was calculated as follows:

$$
\% \text { RFerror }=\frac{100 *(R f \text { standard }-R f \text { sample })}{\text { Rfstandard }}
$$

Rule: If $\mathrm{Rf}_{\text {error }} \leq 5 \%$, the sample is considered valid; if $\mathrm{Rf}_{\text {error }}$ is between $5 \%$ and $10 \%$, the sample is deemed doubtful; if $R f_{\text {error }} \geq 10 \%$, the sample is invalid [2]. 


\section{Quantitative analysis of Quinine sulfate in tablets}

Aliquots of 20 tablets crushed to a powder, equivalent to $100 \mathrm{mg}$ of quinine sulfate, were gently stirred for 15 minutes in $40 \mathrm{ml}$ of acetic anhydride $\mathrm{R}$ and $40 \mathrm{ml}$ of anhydrous acetic acid. And we titrated with perchloric acid $(0.1 \mathrm{~mol} / \mathrm{L})$ using violet crystal as the indicator (from violet to blue and apple green). Each $\mathrm{ml}$ of perchloric acid $(0.1 \mathrm{~mol} / \mathrm{L})$ is equivalent to $26.10 \mathrm{mg}$ of quinine sulfate $\left[\left(\mathrm{C}_{20} \mathrm{H}_{24} \mathrm{~N}_{2} \mathrm{O}_{2}\right)_{2}, \mathrm{H}_{2} \mathrm{SO}_{4} .2 \mathrm{H}_{2} \mathrm{O}\right]$. The test requires that the yield should not be less than $90.0 \%$ and not more than $110.0 \%$ of the amount of quinine sulfate $[29,30]$.

\section{Quantitative analysis of Artemether-Lumefantrine}

The principle consists of extracting Artemether and Lumefantrine from TLC spots and measuring the absorbance at $254 \mathrm{~nm}$. For the Artemether (sample and standard), we carefully scraped the Artemether layer obtained by TLC. We weighed it and diluted it with $2 \mathrm{ml}$ of the $\mathrm{HCl} /$ ethanol mixture $(1 \mathrm{~mol} / \mathrm{L})$ in a test tube. We homogenized on the vortex agitator and placed the test tube in a water-bath at $55^{\circ} \mathrm{C}$ for 5 hours, then cooled to room temperature and centrifuged. For the blank, we proceed in the same way but without Artemether. We measured the resulting solution's absorbance in a $1 \mathrm{~cm}$ layer quartz cell at the maximum wavelength of $254 \mathrm{~nm}$ against a solvent cell containing the blank. The dilution was 38.5

for Artemether $\left(\mathrm{C}_{16} \mathrm{H}_{26} \mathrm{O}_{5}\right)$ in the sample and standard, using the absorptivity value $A_{1}^{1 \%} \mathrm{~cm}=385$ [27]. The percentage content of Artemether $\left(\mathrm{C}_{16} \mathrm{H}_{26} \mathrm{O}_{5}\right)$ in the tablets was calculated as follows:

$$
\text { Yield } \%=\frac{100 *(\text { mean Asorbance sample })}{\text { mean Absorbance standard }}
$$

The requirement of the test is met if the yield is between $95.0 \%-105.0 \%$ of the amount of Artemether $\left(\mathrm{C}_{16} \mathrm{H}_{26} \mathrm{O}_{5}\right)$ and Lumefantrine $\left(\mathrm{C}_{30} \mathrm{H}_{32} \mathrm{Cl}_{3} \mathrm{NO}\right)$. For the lumefantrine analysis, we carefully scraped the layer of Lumefantrine obtained on TLC, and then we weighed it and dissolved it in $2 \mathrm{ml}$ of methanol $\mathrm{R}$ in a test tube. We homogenized on the vortex agitator for 15 minutes and centrifuged. For the blank, the procedure was the same but without Lumefantrine. The absorbance was measured $380 \mathrm{~nm}$ [28].

\section{Data analysis}

We used a scoring system 1 if the requirement is satisfied or 0 if not to evaluate the critical quality attributes - the sum of scores allowed calculating the percentages of global quality satisfaction. A modified psycho-physical Harrington's scale of quality [31] was set as Excellent (0.90-1.00), Good (0.80$0.90)$, Acceptable (0.70-0.80), and Low (0.30-0.70). The risk of treatment failure, death due to untreated disease, or toxicity was high, moderate, or low concerning absence or wrong active ingredient, identity, under-dose, over-dose, disintegration, uniformity of mass, and labeling outcomes. MS Excel 2013 was used to calculate descriptive statistics.

\section{RESULTS}

\section{Global compliance with all quality tests}

Figure 1 shows the satisfaction of each QS batch to the 14 tests performed. Dose(the content strength); No Batch(batch number); Issue(the issued date); Expire(the expiring date); Shelf(the shelf live); Company(the manufacturer); Country(the country of production); Uniformity(the uniformity of mass); Hardness(the resistance); Friability(friction); Disintegration(disintegration time); TLC(chromatogram); Assay(dosage); Mayer(identification of alkaloids). Batches QSB2.2, QSB2.4, QSB3.5, QSB4.6 from Brands 
2, 3 and 4, did not satisfy all required labeling information. Brands 4 and 5 did not contain quinine:

brands 1, 2, and 3 failed the disintegration test. No quinine batch obtained a 100\% score; the maximum score was 92.9\%, corresponding to one failure (QSB1.11, QSB1.8, QS1.1), and the minimum was 35.7\%, corresponding to 9 failures (QS4.6). The most failed tests were disintegration (33.3\%) and assay (41.7\%).

Figure 2 shows the satisfaction of each AL batch to the 13 tests performed. All label information needed was given, but only 5 batches satisfied the assay test. The minimum score for AL batches was $92.3 \%$. The most failed test was the content assay (41.7\%).

\begin{tabular}{|c|c|c|c|c|c|c|c|c|c|c|c|c|c|c|c|c|}
\hline Batch & DOSE & NO BAтCH & ISSUE & EXPIRE & SHELF & COMPANY & COUNTRY & UNIFORMITY & HARDNESS & FRIABILITY & DIIINTEGRATION & TLC & ASSAY & MAYER & TOTAL & $\%$ \\
\hline QSB1.1 & 1 & & & 1 & 1 & 1 & 1 & & & (1) & 0 & (1) & (1) & (1) & 13 & 92.9 \\
\hline QSB1.3 & & & & & 1 & 1 & & & & & 0 & 1 & 0 & 1 & 10 & 71.4 \\
\hline QSB1.8 & & & & & (1) & 1 & & & & & (1) & 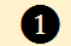 & ( & & 13 & 92.9 \\
\hline QSB1.9 & & & & 1 & (1) & & & & & & & & (0) & & 12 & 85.7 \\
\hline QSB1.11 & & & & 1 & (1) & & 1 & & & & 0 & 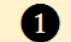 & (1) & 1 & 13 & 92.9 \\
\hline QSB2.2 & & & 1 & 1 & 1 & 0 & (0) & & & (0) & (0) & (1) & (0) & (1) & 9 & 64.3 \\
\hline QSB2.4 & & & 1 & 1 & 1 & (0) & (0) & & (0) & (0) & (0) & (1) & (1) & (1) & 9 & 64.3 \\
\hline QSB3.5 & 1 & & (0) & 1 & 0 & 0 & 0 & & & & 0 & (1) & (1) & 1 & 8 & 57.1 \\
\hline QSB4.6 & (1) & 0 & 0 & 1 & 0 & 0 & 0 & 0 & 1 & (1) & 1 & 0 & (0) & 0 & 5 & 35.7 \\
\hline QSB5.7 & 1 & 1 & 1 & (1) & 1 & (1) & (1) & (0) & 1 & (0) & (1) & (0) & 0 & (0) & 9 & 64.3 \\
\hline QSB5.10 & (1) & & (1) & 1 & 1 & 1 & 1 & 1 & & (1) & 1 & 0 & 0 & 0 & 11 & 78.6 \\
\hline QSB5.12 & 1 & 1 & 1 & (1) & (1) & 1 & 1 & 1 & 1 & (1) & 1 & 0 & 0 & (0) & 11 & 78.6 \\
\hline Total & 12 & 10 & 10 & 12 & 10 & 8 & 8 & 10 & 10 & 8 & 4 & 8 & 5 & 8 & & \\
\hline$\%$ & 100 & 83.3 & 83.3 & 100 & 83.3 & 66.7 & 66.7 & 83.3 & 83.3 & 66.7 & 33.3 & 66.7 & 41.7 & 66.7 & & \\
\hline
\end{tabular}

Figure-1. Quality compliance scores of Quinine batches analyzed

\begin{tabular}{|c|c|c|c|c|c|c|c|c|c|c|c|c|c|c|c|}
\hline ttch & DOSE & NO BATCH & ISSUE & EXPIRE & SHELF & COMPANY & COUNTRY & JMIFORMITY & IARDNESS & RIABLITY D & INTEGRATION & TLC & ASSAY & Total & TOTAL \\
\hline ALB1.1 & & & & & & & 1 & & & 1 & 1 & & & 13 & 100 \\
\hline LB1.4 & & & & & & & & & & & & & & 12 & 92.3 \\
\hline 81.5 & & & & & & & & & & & & & & 12 & 92.3 \\
\hline LB1.7 & & & & & & & & & & & & & & 12 & 92.3 \\
\hline ALB1.8 & & & & & & & & & & & & & & 12 & 92.3 \\
\hline LB11.9 & & & & & & & & & & & & & & 12 & 92.3 \\
\hline LBB1.11 & & & & & & & & & & & & & & 12 & 92.3 \\
\hline LBB1.12 & & & & & & & & & & 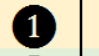 & & & & 13 & 100 \\
\hline ALB2.2 & & & & & & & & & & & & & & 12 & 100 \\
\hline ALB2.3 & & & & & & & & & & & & & & 12 & 92.3 \\
\hline ALB2.6 & & (1) & & & & & & & & & 1 & & 0 & 12 & 92.3 \\
\hline ALB2.10 & & & & & & & & & & & & & & 13 & 100 \\
\hline Total & 12 & 12 & 12 & 12 & 12 & 12 & 12 & 10 & 12 & 12 & 12 & 12 & 5 & & \\
\hline$\%$ & 100 & 100 & 100 & 100 & 100 & 100 & 100 & 83.3 & 100 & 100 & 100 & 100 & 41.7 & & \\
\hline
\end{tabular}

Figure-2. Quality compliance scores of Artemether/Lumefantrine batches analyzed

Legend: $1=$ satisfied; $0=$ not satisfied

Labeling quality 
As presented, the visual inspection shows that 4(30\%) batches of QS-samples (QSB2.2, QSB2.4, QSB3.5, and QSB4.6) did not meet all the labeling requirements. Some information was inaccurate or missing. The labeling on the packages of AL-samples contained all the needed information.

\section{General tests on pharmaceutical technology}

The elements tested were mass uniformity, hardness, friability, and disintegration time. For QS samples, 2 batches (QSB4.6, QSB5.7) did not meet the mass uniformity criteria because more than 3 tablets deviated beyond $\pm 10.0 \%$. The hardness of 2 batches (QSB1.3, QSB3.4) did not lay between $50-150$ Newton. The disintegration time of 8 batches (QSB1.1, QSB1.3, QSB1.8, QSB1.9, QSB1.11, QSB2.2, QSB2.4, and QSB3.5) was out of specification limits. For AL samples, 2 batches (ALB1.4, ALB2.2) did not meet the mass uniformity criteria. All batches satisfied the specification limits of hardness, friability, and disintegration.

\section{Identification of active ingredients}

Identification of QS samples showed that 4 batches (QSB5.7, QSB5.10, QSB5.12, QSB4.6) did not contain quinine sulfate; QSB4.6 had an active ingredient other than quinine sulfate because the $\mathrm{Rf}_{\text {error }}$ was $>10 \%$. Four batches of QS samples failed Mayer's reaction (QSB4.6, QSB5.7, QSB5.10, and QSB5.12).

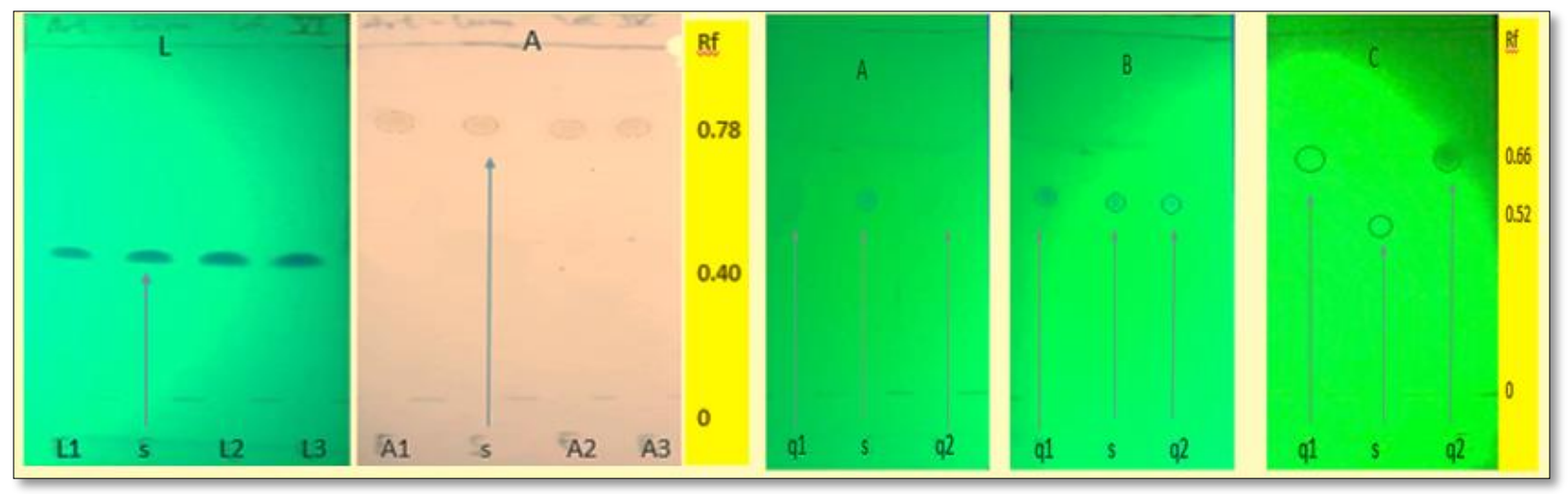

\section{Figure 3 Typical TLC chromatograms of QS and AL samples analyzed}

Figure-3 shows the typical TLC chromatograms obtained. The TLC of Lumefantrine (L), Artemether (A) shows that all batches in triplicate spots gave $\mathrm{Rf}$ similar to the standards(s), with $\mathrm{RF}_{\text {error }}<2 \%$ for all the spots. However, the TLC of quinine shows the absence of quinine sulfate in sample spot $A(q 2)$; the similarity of $\mathrm{Bq} 1$ and $\mathrm{Bq} 2$ spots with the standard (s); the presence of other products different from the quinine standard in $\mathrm{Cq} 1$ and $\mathrm{Cq} 2$.

\section{Content of active ingredients}

Table 2 shows the results of quantitative assays. For QS samples, the batches QSB4.6, QSB4.7, QSB4.10, and QSB4.12 did not contain quinine (Yield=0\%). For AL samples, the yield of Lumefantrine of batches ALB1.5, ALB1.7, ALB1.8, and ALB2.3 was $<90 \%$. The qualitative analysis revealed the absence or insufficient amount of active ingredients or the presence of other components than quinine sulfate in some batches.

Table 2 Results of quantitative assays 


\begin{tabular}{|c|c|c|c|c|}
\hline QS batches & Quinine & AL batches & Artemether & Lumefantrine \\
\hline Batches & Yield (\%) & Batches & Yield (\%) & Yield (\%) \\
\hline QSB1.1 & $96.51 \pm 1.99$ & AL B1.1 & $99.46 \pm 2.93$ & $98.15 \pm 0.49$ \\
\hline QS B1.3 & $94.32 \pm 2.61$ & AL B1.4 & $100.10 \pm 1.76$ & $98.89 \pm 0.82$ \\
\hline QS B1.8 & $101.31 \pm 1.51$ & ALB1.5 & $100.19 \pm 1.91$ & $80.37 \pm 0.40 *$ \\
\hline QS B1.9 & $93.45 \pm 3.01$ & ALB1.7 & $91.81 \pm 1.50$ & $85.61 \pm 0.47 *$ \\
\hline QS B1.11 & $98.69 \pm 3.01$ & ALB1.8 & $90.06 \pm 1.65$ & $87.38 \pm 1.23 *$ \\
\hline QS B2.2 & $94.32 \pm 2.61$ & ALB1.9 & $93.99 \pm 0.58$ & $99.73 \pm 0.97$ \\
\hline QS B2.4 & $98.69 \pm 3.01$ & ALB1.11 & $94.3 \pm 0.29$ & $96.13 \pm 0.35$ \\
\hline QS B3.5 & $99.46 \pm 1.52$ & ALB1.12 & $97.05 \pm 0.45$ & $98.46 \pm 0.98$ \\
\hline QS B4.6 & $0 *$ & ALB2.2 & $96.78 \pm 0.33$ & $100.37 \pm 0.59$ \\
\hline QS B5.7 & $0^{*}$ & ALB2.3 & $100.44 \pm 1.97$ & $82.78 \pm 0.56^{*}$ \\
\hline QS B5.10 & $0 *$ & ALB2.6 & $97.90 \pm 2.64$ & $94.44 \pm 0.62$ \\
\hline QS B5.12 & $0 *$ & ALB2.10 & $97.84 \pm 2.40$ & $98.70 \pm 0.62$ \\
\hline
\end{tabular}

*out-of-specifications

\section{DISCUSSION}

Counterfeiter medicines are the leading cause of resistance, morbidity, mortality, and failure of the public health care system interest [32-36]. Quinine and Artemether/Lumefantrine fixed-dose are on the WHO essential medicines model list for curative malaria [32]. In this study, we assessed the pharmaceutical quality of $Q S$ and $A L$ tablets under the following critical quality requirements: labeling quality, general tests on pharmaceutical dosage forms, content and dissolution, identification, and the presence of unidentifiable impurities in formulations. The findings vigorously back the importance of the counterfeiting phenomenon as decried in numerous studies.

Drug labeling is a legislative requirement to obtain information on drugs such as brand name, pharmaceutical form, manufacture and expiration dates, and route of administration, manufacturer, and country manufacturing [37]. Thus, the investigated products might not have a risk of confusion associated with labeling. The results of the visual inspection on physical characteristics of tablets and labeling information revealed that QS products did not comply with the WHO guideline on the labeling for pharmaceutical products. All QS samples mentioned the dose; $83.3 \%$ mentioned batch number and date of issue, and shelf-life; only $66.7 \%$ mentioned manufacturer and country. All AL-samples complied satisfactorily. A tighter inspection of the label can help suspect wrong products. Often, counterfeiters copy the brand's design or the designation of a product and sometimes the address. In developed countries, anti-counterfeit packaging technologies are being developed [38-40]. The European trend is towards 2D barcodes (anti-Counterfeit Technologies), and the United States has implemented radio frequency identification (RFID)[41]. The probability of detecting the failure in DRC is low. 
According to Good manufacturing practice (GMP), the critical quality attributes include disintegration and dissolution, uniformity of mass, and friability. The disintegration of tablets is a crucial step in releasing the active ingredient to get into the human body; it precludes the bioavailability of the medicine and requires adequate quality and quantity of disintegrating agents [42-44]. Failure to quickly release the active ingredient for conventional formulations has the risk of therapeutic loss or delayed effect onset, explaining the number of deaths. The analysis of AL-brands indicated that all of the samples but one complied with the quality specifications. However, for QS-samples, only 3 out of 12 batches fully satisfied the critical technology attributes. Also, mass uniformity is an alternative test for content uniformity of uncoated and film-coated tablets. Here, defaults of two QS batches and one ALbatch might not affect the content uniformity of the investigated products' dose units. Many studies show that most antimalarial solid dosage forms pass the basic tests, such as the uniformity of mass, for tablets, the content test, but a few pass in vitro product dissolution test required [42-44].

TLC and Mayer's QS identification revealed that 7 out of 12 batches did not contain the active principle. The results of quinine amount indicated that only $41.7 \%$ of investigated products did comply with the Pharmacopoeial specification limit (90-110\%). Contrarily, AL-samples showed excellent scores (>90\%) for Artemether, even though the content of Lumefantrine was under-dose in 4 batches. The risk of treatment failure due to bad quality is significantly higher with QS tablets than AL fixed-dose products. Studies carried out in Rwanda and the East of DR Congo had also shown the under-dosing and the absence of the quinine [11, 45]. One study conducted in DRC [46] on $150 \mathrm{AL}$-samples collected from private pharmaceutical outlets in 8 main cities(Goma, Kikwit, Kinshasa, Kisangani, Lubumbashi, Matadi, Mbandaka, and Mbuji-Mayi) found 3 (2\%) visual inspection failure, 4 (2.7\%) TLC test failure. HPLC assays showed $46(30.7 \%)$ samples had artemether contents below $90 \%$ and $17(11.3 \%)$ above $110 \%$ of the content claimed on the label; 32 (21.7\%) samples had lumefantrine content below 90\%, and 8 (5.3\%) above $110 \%$. Studies in Kenya [47], Burkina Faso [48], and Ethiopia [49] also detected under-dose artemisinin generic products.

According to the WHO, counterfeit AMDs are often sold at low prices because they do not contain the right ingredients. Oral administration is the most widely accepted route due to its convenience in selfadministration and easy manufacturing, which lead to easy counterfeiting. In DRC, pharmacies and free markets are among the potential sellers of inexpensive antimalarial to health facilities and the public. The unemployment rate is high; the average monthly household income remains low [50]. Such poverty leads people to look for cheaper antimalarial products sold in free markets. The situation makes it very hard to detect fake products quickly. Non-pharmacists own most pharmacies, and many are not at all managed by pharmacists. We know that non-pharmacist health professionals are not qualified to detect the quality characteristics of the drugs they prescribe or administer.

\section{CONCLUSION}

The findings show that antimalarial drugs sold in the DRC pharmaceutical market are imported products from various countries, and not all brands are of good quality. African countries are exposed to multiple kinds of counterfeiting favored by poverty, lack of proxy control tools, and inefficacy of regulatory authority. That raises the importance of surveying the quality of all pharmaceutical products imported. Pharmacists should be involved at each step of the medication management system to detect any anomalies to minimize the counterfeiting phenomenon's impact. Simple tests may be of significant help.

\section{List of abbreviations}


AL: Artemether-Lumefantrine

AMDs: Antimalarial drugs

DRC: Democratic Republic of Congo

MQSA: Molecular Quantitative Similarity Analysis

QS: Quinine sulfate

RFID: Radio-frequency identification

TLC: Thin-layer chromatography

USFDA: United States Food and Drug Administration

WHO: World health organization

WMR: World Malaria Report

\section{Declarations}

Ethics approval and consent to participate

Not applicable

Consent for publication

Not applicable

Availability of data and materials

The datasets used and/or analysed during the current study are available from the corresponding author on reasonable request.

Competing interests

The authors declare that they have no competing interests

Funding

No funding

\section{Authors' contribution}

$A O M$ and $A Z M$ designed the study and literature search. AZM, LMN, PMH operated pharmaceutics testing. NHC, FMK, BBZ conducted identification tests. AOM, and JNK revised protocols, supervised and wrote the final draft. All authors reviewed the manuscript.

\section{Authors' details}

Aladin Ombeni Mahano ${ }^{1}$, PharmD, MSc, aladdinmahano@gmail.com, Unit of pharmaceutics Aline Zawadi Mahano ${ }^{1}$, PharmD, alynemahano@gmail.com, Unit of pharmaceutics Nelson Hendwa Cubaka ${ }^{1}$, PharmD, nhendwa@gmail.com, Unit of pharmaceutical chemistry 
Félicien Mushagalusa Kasali ${ }^{1}$, PharmD, Msc, felicienkasali@gmail.com, Unit of pharmacognosy

Benjamin Bavurhe Zirirane ${ }^{1}$, PharmD, benjaminbavurhe2@gmail.com , Unit of pharmacology

Lucien Murhula Namegabe ${ }^{1}$, PharmD, MSc, murhulan@yahoo.fr, Unit of pharmaceutics

Pacifique Murhula Hamuli ${ }^{1}$ PharmD, Msc, hamuli2011@gmail.com, Unit of pharmaceutics

Justin Ntokamunda Kadima ${ }^{1}$, PharmD, Ph.D., ntokamunda13@gmail.com, Unit of pharmacology

Acknowledgment

We acknowledge the contribution of Labo technicians in the department of Pharmacy (UOB)

\section{REFERENCES}

1. WHO. Paludism. Available from: https://www.who.int/topics/malaria/fr/.

2. CDC. Malaria 2015. Available from: https://www.cdc.gov/malaria/about/[fr-fr]-faqs.html.

3. Trampuz A, Jereb M, Muzlovic I, Prabhu RM. Clinical review: Severe malaria. Crit Care. 2003; 7(4):315-23. https://link.springer.com/content/pdf/10.1186/cc2183.pdf.

4. Brooker SJ, Clarke S, Deepika Fernando CWG, Nankabirwa J, Schellenberg D, Greenwood B. Chapter 14 Malaria in Middle Childhood and Adolescence. In: Child and Adolescent Health and Development. 3rd ed. Washington (DC):2017. https://www.ncbi.nlm.nih.gov/books/NBK525246/

5. WHO 2010. World malaria report. Geneva; 2019. https://apps.who.int/iris/bitstream/handle/10665/330011/9789241565721-eng.pdf.

6. WHO 2020. Malaria. https://www.who.int/news-room/fact-sheets/detail/malaria

7. MMV. Medicines for Malaria Venture M. Developing antimalarials to save lives. Available from: https://www.mmv.org/malaria-medicines/malaria-facts-figures. [Accessed 2020 Aug 25].

8. Basco L. Molecular epidemiology of malaria in Cameroon-XIX. Quality of antimalarial drugs used for self-medication. Am J Trop Med Hyg. 2004; 70:245-50.

9. Winstanley $P$, Ward S, Snow R, Breckenridge A. Therapy of falciparum malaria in sub-Saharan Africa: from molecule to policy. Clin Microbiol Rev. 2004 Jul; 17(3):612-37.

10. Takata J, Sondo P, Humphreys GS, Burrow R, Maguire B, Hossain MS, Debashish Das, Commons RJ, Price RN. The World Wide Antimalarial Resistance Network Clinical Trials Publication Library: A Live, Open-Access Database of Plasmodium Treatment Efficacy Trials. Am J Trop Med Hyg. 2020; 103(1):359-68.

11. Habyalimana V, Mbinze JK, Yemoa AL, Kadima NJL, Hubert P, Roland Marini RD. Simple LC Isocratic Methods Development, Validation, and Application in the Analysis of Poor Quality Antimalarial Medicines. American Journal of Analytical Chemistry. 2017; 8:582-603. doi: 10.4236/ajac.2017.89042

12. OMS. Médicaments essentiels frauduleux depuis l'Asie du Sud et de l'Est vers l'Afrique de I'Ouest. 2012. https://www.unodc.org/documents/toc/Reports/TOCTAWestAfrica/West_Africa_TOC_FRAUD_ MEDICINES_FR.pdf

13. Frankish H. WHO steps up campaign on counterfeit drugs. Lancet. 2003;362:1730. https://doi.org/10.1016/S0140-6736(03)14891-X 
14. Kelesidis T, Falagas ME. Substandard/counterfeit antimicrobial drugs. Clin Microbiol Rev. 2015; 28(2):443-64.

15. MSP Ministere de la santé publique R. Rapport narratif: Profil pharmaceutique de la République Démocratique du Congo 2011.

16. National Malaria Control Program P. Evaluation of the impact of malaria control interventions on all-cause mortality in children under five in the Democratic Republic of the Congo from 2005 to 2015. Kinshasa; 2018. https://www.pmi.gov/docs/default-source/default-documentlibrary/pmi-reports/drc-malaria-impact-evaluation-group-executive-summaryfrench.pdf?sfvrsn=3. Accessed 2020 Jan 13.

17. WHO. Artemisinin resistance and artemisinin-based combination therapy efficacy. Global Malaria 2019. https://www.who.int/malaria/areas/treatment/drug_efficacy/en/

18. WHO. Uniformity of mass for single-dose preparations. Ninth. The International Pharmacopoeia (Ph.Int). 2019 [cited 2020 Jun 17]. https://apps.who.int/phint/pdf/b/7.5.3.5.2-Uniformity-ofmass-for-single-dose-preparations.pdf

19. EDQM. 2.9.7. Friability of uncoated tablets. In: European Pharmacopoeia (Ph Eur)Ph Eur. 6th ed. European Directorate for the Quality of Medicines Strasburg.2008; p. 278. http://www.uspbpep.com/ep60/2.9. 7.

20. EDQM. 2.9.8. Resistance to crushing of tablets. In: European Pharmacopoeia (Ph Eur). 6th ed. European Directorate for the Quality of Medicines Strasburg; 2008; p. 279. http://www.uspbpep.com/ep60/2.9. 8.

21. EDQM. 2.9.1. Disintegration of tablets and capsules. 6th ed. European Pharmacopoeia (Ph. Eur). European Directorate for the Quality of Medicines Strasburg; 2008; p.263. http://www.uspbpep.com/ep60/2.9. 1.

22. WHO. Disintegration test for tablets and capsules. Ninth. The International pharmacopoeia (Ph.Int). World Health Organization; 2019. https://apps.who.int/phint/pdf/b/7.5.4.5.3Disintegration-test-for-tablets-and-capsules.pdf

23. WHO. Quinine sulfate tablets (Quinini sulfas compressi). Ninth. The International Pharmacopoeia. https://apps.who.int/phint/2019/index.html\#d/b.6.2.2.114.

24. Richard J, Peter P, Peter G, Schuster A. Tests de chromatographie sur Couche Mince, Global Pharma Health Fung(GPHF), Allemagne. 2016. 209p.

25. Gaur R, Azizi M, Hansal P, K H. British pharmacopoeia vo, Stationery Office on behalf of the medicines and Healthcare product Regulatory Agency (MHRA), London, ISBN 9780113227990. 2009.

26. Rwo J, Dwornik K, Fischer K. Thin Layer Chromatographic Tests. In: A Concise Quality Control Guide on Essential Drugs and other Medicines. 2nd ed. Darmstadt: Global Pharma Health Fund (GPHF); 2014. https://www.gphf.org/images/downloads/DemoMinilabSupplement2014English.pdf

27. WHO. Artemether tablets. In: The International Pharmacopoeia (PhInt). 6th ed. Geneva; 2016. https://apps.who.int/phint/2016/index.html\#d/b.6.2.2.17.

28. Karajgi S. R., Tanveer AR and Kalyane N.V. Simultaneous Determination of Artemether and Lumefantrine by Area Under Curve UV Spectrophotometric Method J. Pharm. Sci. \& Res. Vol. 8(6), 2016, 506-511. 
29. WHO. QUININE SULFATE TABLETS: Final text for addition to The International Pharmacopoeia (November 2008) https://www.who.int/medicines/publications/pharmacopoeia/Quinine-sultab QAS07 219FINAL.pdf

30. S Cholvy. Practical applications of protometry in anhydrous media for the analytical control of some pharmaceutical preparations] Ann Pharm Fr. 1960; 18:138-44. https://pubmed.ncbi.nlm.nih.gov/13809987/.

31. Bikbulatov ES, Stepanova IE. Harrington's desirability function for natural water quality assessment. Russ J Gen Chem. 2011;81:2694-704.

32. World Health Organization W. World Health Organization Model List of Essential Medicines. 21st ed. Geneva: World Health Organization 2019. 1-60 p. https://apps.who.int/iris/bitstream/handle/10665/325771/WHO-MVP-EMP-IAU-2019.06eng.pdf

33. Newton PN, Green MD, Mildenhall DC, Plançon A, Nettey H, Nyadong L, et al. Poor quality vital antimalarials in Africa - an urgent neglected public health priority. 2011; 1-22.

34. Rana GS. Counterfeit Defeat Brands. SSRN Electron J. 2005. https://papers.ssrn.com/sol3/Delivery.cfm/SSRN ID701189 code464609.pdf?abstractid=70118 9\&mirid=1

35. WHO. Counterfeit medical products. Geneva; 2010. http://apps.who.int/gb/ebwha/pdf_files/WHA63/A63_23-en.pdf

36. World Health Organization W. Does quality of medicines matter? Geneva; 2009. http://www.who.int/medicines/services/counterfeit/faqs/QACounterfeit-October2009.pdf

37. Nayyar GML, Breman JG, Newton PN, Herrington J. Poor-quality antimalarial drugs in Southeast Asia and sub-Saharan Africa. Lancet Infect Dis. 2012;12(6):488-96. https://doi.org/10.1016/S1473-3099(12)70064-6

38. Moore S. Labelling and its role in pharmaceutical packaging. Int Pharm Ind. 2012; 4(3):114-8. Available from: http://ipimediaworld.com/wp-content/uploads/2012/09/Pages-from-IPIVolume4Issue3-35.pdf

39. Bansal D, Malla S, Gudala K, Tiwari P. Anti-counterfeit technologies: a pharmaceutical industry perspective. Sci Pharm. 2012/10/09. 2013; 81(1):1-13.

40. Shah RY, Prajapati PN, Agrawal YK. Anticounterfeit packaging technologies. J Adv Pharm Technol Res. 2010 Oct; 1(4):368-73.

41. CDC Centers for Disease Control and Prevention. Epi InfoTM: Population Survey or Descriptive Study. 7th ed. Division of Health Informatics \& Surveillance. Atlanta, Georgia: https://www.cdc.gov/epiinfo/user-guide/statcalc/samplesize.html

42. Alğin Yapar E. Orally disintegrating tablets: An overview. J Appl Pharm Sci. 2014; 4(2):118-25.

43. Sastry S V, Nyshadham JR, Fix JA. Recent technological advances in oral drug delivery - a review. Pharm Sci Technolo Today. 2000;3(4):138-45.

44. WHO World Health Organization W. Does quality of medicines matter? Geneva; 2009. http://www.who.int/medicines/services/counterfeit/faqs/QACounterfeit-October2009.pdf

45. Namegabe LM, Kadhesi MT, Hamuli PM, Mahano AO, Brioen PB. Quality Control of Quinine in Pharmaceutical Forms Tablets Found in East of the Democratic Republic of Congo. Am J Anal Chem. 2019; 10(09):415. 
46. Mufusama JP, Ndjoko Loset K, Feineis D, Hoellein L, Holzgrabe U, Bringmann G. Quality of the antimalarial medicine artemether - Lumefantrine in 8 cities of the Democratic Republic of the Congo. Drug testing and analysis Jun $122018 \mathrm{https} / / /$ doi.org/10.1002/dta.2420

47. Atemnkeng MA, De Cock K, Plaizier-Vercammen J. Quality control of active ingredients in artemisinin-derivative antimalarials within Kenya and DR Congo. Trop Med Int Health. 2007; 12(1):68-74. https://onlinelibrary.wiley.com/doi/epdf/10.1111/j.1365-3156.2006.01769.x

48. Tipke M, Diallo S, Coulibaly B, Störzinger D, Hoppe-Tichy $T$, Sie A, et al. Substandard antimalarial drugs in Burkina Faso. Malar J. 2008; 7(1):95. https://doi.org/10.1186/1475-2875-7-95

49. Belew S, Suleman S, Mohammed T, Mekonnen $Y$, Duguma M, Teshome H, Bayisa B, Wynendaele E, D'Hondt M, Duchateau L, and De Spiegeleer B. Quality of fixed dose artemether/lumefantrine products in Jimma Zone, Ethiopia. Malar J. 2019;18:236 https://doi.org/10.1186/s12936-019-2872-1

50. UNDP United Nations Development Programme. South-Kivu Province: Summary Profile, Poverty and Household Living Conditions. 2009.

http://www.undp.org/content/dam/dem rep congo/docs/povred/UNDP-CD-Profil-PROVINCESud-Kivu.pdf 
Figures

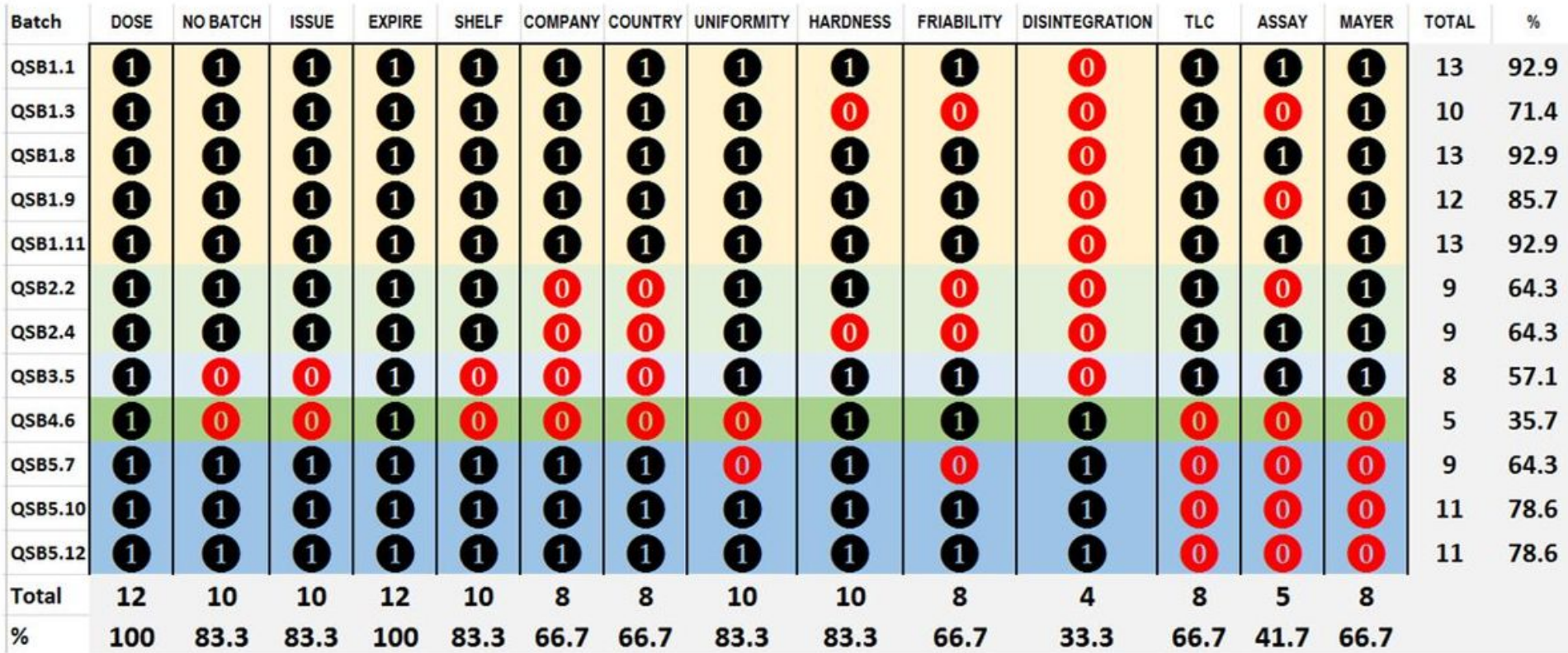

Figure 1

Quality compliance scores of Quinine batches analyzed

\begin{tabular}{|c|c|c|c|c|c|c|c|c|c|c|c|c|c|}
\hline Batch & DOSE & NO BATCH & ISSUE & EXPIRE & SHELF & COMPANY & COUNTRY & UNIFORMITY HARDNESS & FIABILITY DISINTEGRATION & TLC & ASSAY & Total & TOTAL \\
\hline ALB1.1 & & & & & & & & 1 & 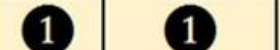 & & & 13 & 100 \\
\hline ALB1.4 & & & & & & & & & & & & 12 & 92.3 \\
\hline ALB1.5 & & & & & & & & & & & & 12 & 92.3 \\
\hline ALB1.7 & & & & & & & & & & & & 12 & 92.3 \\
\hline ALB1.8 & & & & & & & & & & & & 12 & 92.3 \\
\hline ALB1.9 & & & & & & & & & & & & 12 & 92.3 \\
\hline ALB1.11 & & & & & & & & & & & & 12 & 92.3 \\
\hline ALB1.12 & & & & & & & & & & & & 13 & 100 \\
\hline ALB2.2 & & & & & & & & & & & & 12 & 100 \\
\hline ALB2.3 & & & & & & & & & & & & 12 & 92.3 \\
\hline ALB2.6 & & & & & & & & & & 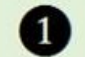 & & 12 & 92.3 \\
\hline ALB2.10 & & & & & & & & & & & & 13 & 100 \\
\hline Total & 2 & 12 & 12 & 12 & 12 & 12 & 12 & 0 & 12 & 12 & 5 & & \\
\hline$\%$ & 100 & 100 & 100 & 100 & 100 & 100 & 100 & 83.3 & 100 & 100 & 41.7 & & \\
\hline
\end{tabular}

Figure 2

Quality compliance scores of Artemether/Lumefantrine batches analyzed Legend: $1=$ satisfied; $0=$ not satisfied 


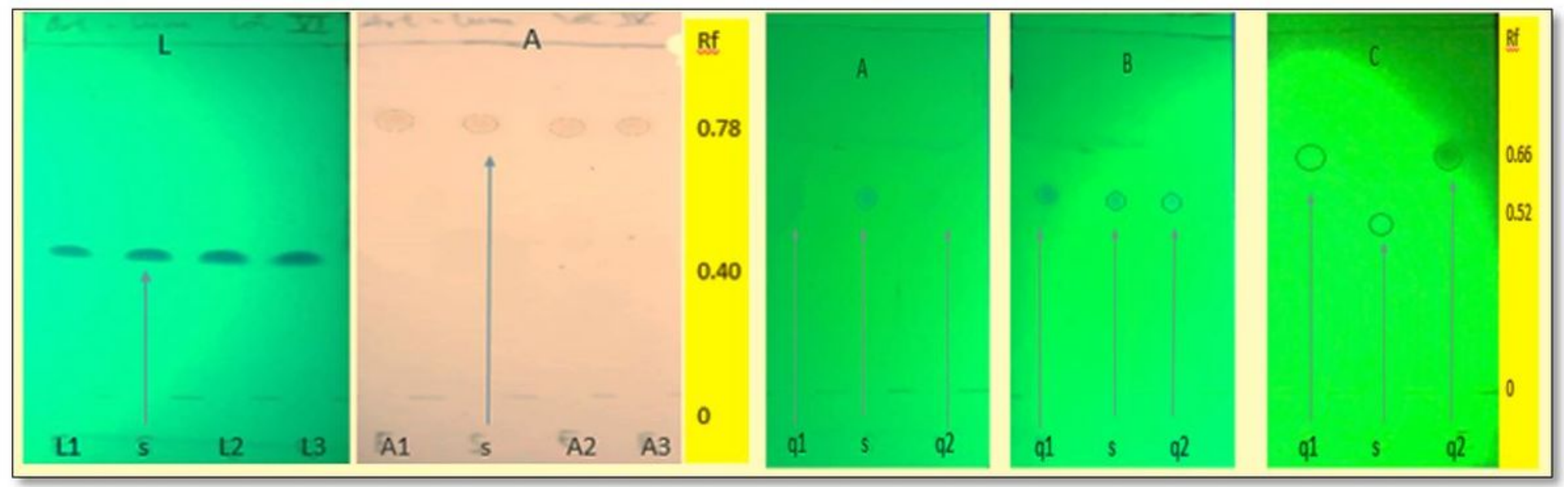

Figure 3

Typical TLC chromatograms of QS and AL samples analyzed 